\title{
Rationing in a Pandemic: Lessons from Italy
}

\section{Lucia Craxi $^{1}$ (1) $\cdot$ Marco Vergano $^{2} \cdot$ Julian Savulescu ${ }^{3,4} \cdot$ Dominic Wilkinson $^{3,5}$}

Received: 23 April 2020 / Revised: 13 May 2020 / Accepted: 14 May 2020/

Published online: 16 June 2020

(C) National University of Singapore and Springer Nature Singapore Pte Ltd. 2020

\begin{abstract}
In late February and early March 2020, Italy became the European epicenter of the COVID-19 pandemic. Despite increasingly stringent containment measures enforced by the government, the health system faced an enormous pressure, and extraordinary efforts were made in order to increase overall hospital beds' availability and especially ICU capacity. Nevertheless, the hardest-hit hospitals in Northern Italy experienced a shortage of ICU beds and resources that led to hard allocating choices. At the beginning of March 2020, the Italian Society of Anesthesia, Analgesia, Resuscitation, and Intensive Care (SIAARTI) issued recommendations aimed at supporting physicians in prioritizing patients when the number of critically ill patients overwhelm the capacity of ICUs. One motivating concern for the SIAARTI guidance was that, if no balanced and consistent allocation procedures were applied to prioritize patients, there would be a concrete risk for unfair choices, and that the prevalent "first come, first served" principle would lead to many avoidable deaths. Among the drivers of decision for admission to ICUs, age, comorbidities, and preexisting functional status were included. The recommendations were criticized as ageist and potentially discriminatory against elderly patients. Looking forward to the next steps, the Italian experience can be relevant to other parts of the world that are yet to see a significant surge of COVID19: the need for transparent triage criteria and commonly shared values give the Italian recommendations even greater legitimacy.
\end{abstract}

Keywords COVID-19 $\cdot$ Allocation $\cdot$ Resources $\cdot$ Rationing $\cdot$ Italy

\section{Introduction}

In late February and early March 2020, while infection rates in China fell, Italy became the European epicenter of the coronavirus (SARS-CoV-2) 2020 epidemic. At the beginning of May 2020, Italy entered the so called phase two, consisting in a progressive reopening of business and social activities while

Lucia Craxì

lucia.craxi@unipa.it

Extended author information available on the last page of the article 
monitoring the eventual raise of the epidemic curve. "Phase two" posed a number of ethical questions, such as finding a new balance between personal liberties and public health, privacy concerns from the use of movement tracking apps, and down the line access to vaccines or improved medications. We think that it is, however, important to look back and determine which lessons can be derived from the way Italy confronted the scarcity of medical resources available to confront the epidemic, especially since this experience can prove invaluable for other countries that are still facing the epidemic peak. In the paper, we analyze the features of the Italian recommendations, why the raised heated debate and why it is important to have ethical guidelines and balanced and consistent allocation procedures to prioritize patients.

\section{The Recommendations issued by the Italian Society of Anesthesia, Analgesia, Resuscitation, and Intensive Care}

In March and April 2020, a huge effort was made by the national government to flatten the epidemic surge by enforcing increasingly stringent containment measures, in order to reduce the impact of the outbreak on the health system. Despite facing a likely major social and economic crisis, the Italian Government imposed a nationwide lockdown on 9 March: prohibition of all movements of people within the whole territory, and closure of all non-essential business activities.

Some think a systematic and strong response arrived too late (Pisano et al. 2020); such measures inevitably have a delayed impact, and hospitals were hit by what has been called a medical "tsunami," with high caseload punctuated by a stream of deaths.

The enormous challenge for the health system - facing a dramatic shortage of ICU beds and staff-has been how to meet the medical needs of patients affected by COVID-19. Even though authorities state that no cases of people who failed to get into intensive care have been reported, many Italian physicians working in ICUs in Northern Italy have stated otherwise, as has the Mayor of Bergamo, one of the hardesthit cities (ANSA 2020; Nacoti et al. 2020; Rosenbaum 2020; Guerzoni 2020). Professionals experienced uncertainty and distress about how to allocate the dramatically scarce resources available, as that situation was unprecedented for everyone: in some hospitals, at the peak of the surge, the rationing involved not only ventilators but oxygen as well.

At the beginning of March, some hospitals around Milan were already collapsing (some of them admitting more than 200 patients with severe respiratory failure every day). As difficult allocation choices were already being made, clinicians (including one of the authors, MV) of the ethics section of the Italian Society of Anesthesia, Analgesia, Resuscitation, and Intensive Care (SIAARTI) were asked to publish guidance on the allocation of limited resources. They worked between shifts to construct the recommendations (Box 1) that sparked a heated debate immediately after the release. 
Box 1 Key elements of SIAARTI recommendations (Vergano et al. 2020a, b)

1. When the availability of resources is overwhelmed by their need, a decision to deny access to one or more life-sustaining therapies, solely based on the principle of distributive justice, may ultimately be justified

2. Criteria for allocation should be flexible and adapted locally in response to available resources, the potential for patient transfer, and the ongoing or foreseen number of admissions

3. An age limit for admission to the ICU may ultimately need to be set

4. Together with age, the comorbidities and functional status of any critically ill patient should be carefully evaluated

5. Every admission to the ICU should be considered and communicated as an "ICU trial." The appropriateness of life-sustaining treatments should be re-evaluated daily

The recommendations issued by SIAARTI suggest that, if a choice to ration medical equipment and intervention is needed, the maximum individual benefit in terms of expected life years - likelihood of survival plus remaining likely years of a patient's life - should be prioritized. According to this principle, the recommendations suggested evaluating age, comorbidities, and functional status of any critically ill patient. This was subsequently criticized as ageist, as well as "unconstitutional" and discriminatory against elderly patients (FNOMCeO 2020; Quotidiano Sanità 2020a, b; Rodriquez 2020). It was perceived as not consistent with the values on which the healthcare system is grounded.

According to the SIAARTI guidance, the drivers of decision for admission to ICU should be the clinical picture taking into account "biological" (not mere chronological) age, comorbidities, and preexisting functional status. This kind of "soft" utilitarian approach is already applied in Italy in specific fields of dramatically scarce resources, such as organ transplants (Cillo et al. 2015). This approach is justified by the need to maximize the achievable benefit in terms of life years gained, thus optimizing the use of available resources: not only the probability of survival and the "greatest life expectancy" are considered, but also the predicted length of the ICU stay and hence the use of intensive care resources. Nonetheless, this kind of approach is the opposite of the egalitarianism that pervades the wider Italian healthcare system.

Sometimes in pursuing what is good, we run the risk of forgetting what is fair. In emergencies, the patient-centered "duty to care" needs to be balanced with publicfocused duties to promote equality of persons and equity in distribution of risks and benefits. Also, individual allocating decisions must be supported by fair institutional processes that may include strategies such as preparing, conserving, substituting, adapting, re-using, and re-allocating resources (Hick et al. 2020).

In every single country facing COVID-19 emergency, if no ethical guidelines or balanced and consistent allocation procedures are applied to prioritize patients, there is a concrete risk for unfair choices (Emanuel et al. 2020). Should the shortage arise with no rationing plan in action, decisions would be left to the ruling of local healthcare and hospital authorities or to the clinician's judgment in the heat of the moment, resulting in approaches both inconsistent and uncoordinated.

One motivating concern for the SIAARTI guidance was the real chance that the prevalent criterion would be "First come, First served." Such an approach appears to remove responsibility for choice over life and death, and can be thought as avoiding having to make ethically fraught choices between patients. We will only point out in passing that from an ethical standpoint, there is no actual difference between action and 
inaction when they both cause harm and injustice. Choosing First come, First served is to be responsible for the foreseeable, avoidable deaths of many people in a pandemic. Moreover, this approach would also carry the huge risk of social unrest and riots due to the rush to obtain hospital beds, or at the very least hospital overcrowding, with the ensuing risk of further spread of infection.

Major inequities would also arise from a "self-made" utilitarian approach by the clinicians left to their own individual intuitions. The risk of arbitrariness and disparities of judgment is only partially reduced by the recommendations that do not set specific thresholds and state that cutoffs "must remain flexible." The aim is to provide a guidance, not a substitution of the individual clinical judgment.

Last but not the least, individual physicians would be, as it happened in Italy, under a tremendous moral distress facing such a terrible task of improvising decisions about whom to treat. They would literally be out on an ethical limb.

In Italy, as elsewhere in the world, we were dramatically unprepared for such a startling emergency, and not just because we had not enough ICU beds, staffing, or funding. We were not prepared at all to face such dramatic choices. In retrospect, the SIAARTI recommendations might have been written differently. It would have been better to have had a chance to involve members of the wider community in reflection on how to make decisions in the event of such a health emergency, as was done in Maryland in the USA in 2012-2015 (Daugherty Biddison et al. 2019). In Maryland, multiple forums were held with the general public and with healthcare workers and disaster professionals using a deliberative democracy approach. Input from citizens was then fed into policy recommendations developed by an expert working group. This kind of approach would have given the recommendations greater legitimacy and might have provided additional support to clinicians.

\section{Conclusions}

We do not know what the future will be like after the pandemic, but it is clear that we should try to rethink the whole issue of allocation of scarce resources in emergency conditions, finding out commonly shared and accepted values to construct a contingency plan with sound and consistent ethical guidelines and proper structures - such as triage committees - to help apply guidelines, relieving the individual front-line clinicians of that burden. The approach is similar to other settings, but this is not acknowledged by the general public, or better, by the critics of the triage recommendations.

Now more than ever, we are aware that a universal, functional, and proactive public healthcare system has the best chances of appropriately facing an unforeseen outbreak of a viral disease. Its full functionality is important at the early stage, when no specific immunization or treatment interventions are available, since it guarantees proper infrastructures to mobilize a testing regime that provides the data that health-policy leaders need to make decisions, and it guarantees a fair and consistent access to supportive care. It will become crucial later, when drugs and vaccines will hopefully be available, to define their price and deliver them widely, effectively, and fairly. We do not know yet if this hard time will turn into a global catastrophe, but should learn from the history of past epidemics that one of the highest risks is to give wrong priorities (Jones 2020) (Box 2). 


\section{Box 2 Key lessons from Italy}

1. In emergencies, the patient-centered "duty to care" needs to be balanced with public-focused duties to promote equality of persons and equity in distribution of risks and benefits.

2. In emergencies, when medical resources available are scarce, the first-come-first-served approach should be rejected.

3. As the development of rapid ethical guidance in emergency is difficult and politically fraught, an advance planning for intensive care - including decision-making in the event of overwhelming demand — is needed. 4. A political and public engagement/education in the ethics of resource allocation is needed to clarify priorities and values if they are to be reflected in allocation.

Author Contributions LC conceived the paper and constructed a first draft. MV, JS, and DW elaborated arguments and contributed to subsequent drafts of the paper. All authors revised the document for critical intellectual input, and all authors approved the final version.

Funding Information JS and DW received support from the Uehiro Foundation on Ethics and Education, and the Wellcome Trust via the Wellcome Centre for Ethics and Humanities (WT203132) and JS from the Wellcome Trust via the Responsibility and Healthcare project (WT104848). Through his involvement with the Murdoch Children's Research Institute, JS was supported by the Victorian Government's Operational Infrastructure Support Program.

\section{Compliance with Ethical Standards}

Conflict of Interest Dr Savulescu reports grants from Wellcome Trust and grants from Uehiro Foundation on Ethics and Education, during the conduct of the study. Dr Vergano reports that he was the lead author on the SIAARTI COVID-19 clinical ethics recommendations. There are no other declarations.

\section{References}

ANSA. 2020. Coronavirus, Borrelli: "Mancano posti in terapia intensiva? Non ci risulta". ANSA, 20 March 2020. Accessed 3 April 2020. https:/www.ansa.it/sito/videogallery/italia/2020/03/20/coronavirusborrelli-mancano-posti-in-terapia-intensiva-non-ci-risulta_5746bc30-b752-4ee1-903e-55a515482070. html.

Cillo, U., P. Burra, V. Mazzaferro, L. Belli, A.D. Pinna, M. Spada, A. Nanni Costa, and P. Toniutto, on behalf of I-BELT (Italian Board of Experts in the Field of Liver Transplantation). 2015. A multistep, consensusbased approach to organ allocation in liver transplantation: Toward a "blended principle model". American Journal of Transplantation 15 (10): 2552-2561. https://doi.org/10.1111/ajt.13408.

Daugherty, Biddison, E. Lee, Ruth Faden, Howard S. Gwon, Darren P. Mareiniss, Alan C. Regenberg, Monica Schoch-Spana, Jack Schwartz, and Eric S. Toner. 2019. Too many patients...a framework to guide statewide allocation of scarce mechanical ventilation during disasters. Chest 155 (4): 848-854. https://doi.org/10.1016/j.chest.2018.09.025.

Emanuel, Ezekiel J., Govind Persad, Ross Upshur, Beatriz Thome, Michael Parker, Aaron Glickman, et al. 2020. Fair allocation of scarce medical resources in the time of Covid-19. New England Journal of Medicine 382: 2049-2055. https://doi.org/10.1056/NEJMsb2005114.

FNOMCeO (Federazione nazionale degli Ordini dei Medici Chirurghi e Odontoiatri). 2020. Anelli (FNOMCeO) su documento Siaarti: "Nostra guida resta ilCodice deontologico". FNOMCeO, 7 March 2020. https://portale.fnomceo.it/anelli-fnomceo-su-documento-siaarti-nostra-guida-resta-ilcodicedeontologico/. Accessed 3 April 2020.

Guerzoni, Monica. 2020. Coronavirus, Gori su Twitter: pazienti "lasciati morire". Poi si scusa. Corriere della Sera, 11 March 2020. https://www.corriere.it/politica/20_marzo_11/coronavirus-gori-denuncia-pazientilasciati-morire-poi-si-scusa-655be6a2-638e-11ea-9cf4-1c175ff3bb7c.shtml?refresh_ce-cp. Accessed 3 April 2020. 
Hick, John L., Dan Hanfling, Matthew K. Wynia, and Andrew T. Pavia. 2020. Duty to Plan: Health Care, Crisis Standards of Care, and Novel Coronavirus SARSCoV-2. NAM Perspectives. https://doi. org/10.31478/202003b.

Jones, David S. 2020. History in a crisis - lessons for Covid-19. New England Journal of Medicine 382: 16811683. https://doi.org/10.1056/NEJMp2004361.

Nacoti, Mirco, Andrea Ciocca, Angelo Giupponi, Pietro Brambillasca, Federico Lussana, Michele Pisano, et al. 2020. At the epicenter of the Covid-19 pandemic and humanitarian crises in Italy: Changing perspectives on preparation and mitigation. NEJM Catalyst https://doi.org/10.1056/CAT.20.0080.

Pisano, Gary P., Sadun, Raffaella, and Zanini, Michele. 2020. Lessons from Italy's response to coronavirus. Harvard Business Review, 27 March 2020. https://hbr.org/2020/03/lessons-from-italys-response-tocoronavirus. Accessed 3 April 2020.

Quotidiano Sanità. 2020a. Coronavirus. Fnopi sul documento degli anestesisti-rianimatori: "Ssn non lasci solo nessuno". Quotidiano Sanità, 10 March 2020. https://www.quotidianosanita.it/scienza-e-farmaci/articolo. php?articolo_id=82353. Accessed 3 April 2020.

Quotidiano Sanità. 2020b. Coronavirus. Geriatri: "No a Rupe Tarpea, la soluzione non è sacrificare gli anziani”. Quotidiano Sanità, 9 March 2020. http://www.quotidianosanita.it/stampa_articolo. php?articolo_id=82299. Accessed 3 April 2020.

Rodriquez, Giovanni. 2020. Coronavirus. "Non siamo in guerra. Ci sono un Ssn e un sistema Paese in grado di dare risposte adeguate". Intervista a Renato Balduzzi sul documento degli anestesisti-rianimatori. Quotidiano Sanità, 11 March 2020. http://www.quotidianosanita.it/scienza-efarmaci/articolo. php?articolo_id=82425. Accessed 3 April 2020.

Rosenbaum, Lisa. 2020. Facing Covid-19 in Italy - ethics, logistics, and therapeutics on the epidemic's front line. New England Journal of Medicine 382: 1873-1875. https://doi.org/10.1056/NEJMp2005492.

Vergano, Marco, Guido Bertolini, Alberto Giannini, Giuseppe R. Gristina, Sergio Livigni, Giovanni Mistraletti, Luigi Riccioni, and Flavia Petrini. 2020a. SIAARTI recommendations for the allocation of intensive care treatments in exceptional, resource-limited circumstances. Minerva Anestesiologica. https://doi.org/10.23736/S0375-9393.20.14619-4.

Vergano, Marco, Guido Bertolini, Alberto Giannini, Giuseppe R. Gristina, Sergio Livigni, Giovanni Mistraletti, Luigi Riccioni, and Flavia Petrini. 2020b. Clinical ethics recommendations for the allocation of intensive care treatments in exceptional, resource-limited circumstances: The Italian perspective during the COVID-19 epidemic. Critical Care 24: 165. https://doi.org/10.1186/s13054-020-02891-w.

Publisher's Note Springer Nature remains neutral with regard to jurisdictional claims in published maps and institutional affiliations.

\section{Affiliations}

\section{Lucia Craxì $^{1}$ - Marco Vergano ${ }^{2}$ - Julian Savulescu ${ }^{3,4} \cdot$ Dominic Wilkinson $^{3,5}$}

1 Department of Biomedicine, Neuroscience and Advanced Diagnostics (Bi.N.D.), University of Palermo, Palermo, Italy

2 Department of Anesthesia and Intensive Care, San Giovanni Bosco Hospital, Turin, Italy

3 Wellcome Centre for Ethics and Humanities, University of Oxford, Oxford, UK

4 Murdoch Children's Research Institute and Melbourne Law School, University of Melbourne, Melbourne, Australia

5 John Radcliffe Hospital, Oxford, UK 